\title{
An onset-onset law for one case of apparent motion and metacontrast
}

DANIEL KAHNEMAN 1

CENTER FOR COGNITIVE STUDIES, HARVARD UNIVERSITY

Ss rated the quality of apparent motion and of metacontrast in computer-controlled sequences of two or of three outlined squares. For brief stimuli, the dependence of the two effects on temporal factors of stimulation is virtually identical. Motion and metacontrast depend solely on the asynchrony of onsets between the two exposures (SOA) over a wide range of duration and interstimulus intervals (ISI). Metacontrast suppression is interpreted as a case of impossible motion. The temporal determinants of apparent motion are summarized in a model in which the effect occurs when the temporal overlap between the perceptual responses to the successive stimuli is intermediate in value.

The following sequence of visual stimuli often elicits reports of apparent motion: A square patch of light is briefly exposed; shortly after that exposure, a similar patch is briefly presented in another location. With appropriate values of spatial and temporal separation, a single illuminated square appears to be moving smoothly to right or left. Now consider a slight modification of this display: a single square, followed by two others, simultaneously presented to the right and left of it. These are conditions for metacontrast suppression; the initial square often fails to be seen and the two flanking squares are seen in motion away from the center. The present article is concerned with the relation between apparent motion and metacontrast suppression, and with some important regularities which they share.

Metacontrast is usually defined (Alpern, 1952, 1953) as the reduction in brightness of a stimulus caused by subsequent stimulation of an adjacent area. Alpern (1952) has reviewed several experimental arrangements in which such reductions are observed. Metacontrast suppression is the extreme case in which the first stimulus is reported to be phenomenally absent. Metacontrast suppression, so defined, has been observed in several variants of the threeobject display described above (Alpern, 1952; Fehrer \& Raab, 1962; Fehrer \& Smith, 1962). The sequence of exposures is obviously similar to the two-object display which elicits reports of beta motion.

Werner $(1935,1940)$ introduced another arrangement which produces metacontrast suppression: a disk followed by a surrounding ring. The disk often fails to be seen (Kolers, 1962; Schiller, 1965; Schiller \& Smith, 1966). The disk-ring sequence is related to the conditions which elicit report of expansive motion; such motion is seen, for example, when a small disk is followed by a large concentric disk.

In spite of the similarity between the conditions which elicit metacontrast and apparent motion, metacontrast effects are traditionally grouped with phenomena of backward masking (Kahneman, submitted; Raab, 1963), and are not even mentioned in recent surveys of apparent motion (Spigel, 1965). This classification ignores several points of similarity between apparent motion and metacontrast:

(1) When metacontrast suppression is complete, the two squares in the terminal display are usually seen in motion away from one another. Experiences of motion in the metacontrast situation have often been noted (Fehrer \& Raab, 1962; Fehrer \& Biederman, 1962; Schiller \& Smith, 1966; Toch, 1956).

(2) When the first and second segments of the metacontrast display are similar in energy and contrast, metacontrast suppression is a U-shaped function of the temporal separation between them (Fehrer \& Smith, 1962; Kolers, 1962; Kolers \& Rosner, 1960; Schiller \& Smith, 1966; Werner, 1935). Optimal motion is also a U-shaped function of temporal separation.

(3) At temporal separations which are too short for complete suppression and for optimal motion, the initial stimulus is seen, but its brightness and contrast are much reduced. This reduction of brightness is not specific to metacontrast; it has also been noted in descriptions of apparent motion (Wertheimer, 1912; Korte, 1915). It is easy to demonstrate that the dimming effects which accompany partial motion are not much different from those which define partial metacontrast. In the three-square display, an interval may be selected at which the first square appears distinctly dimmer than its neighbors. The central square will remain dim even when one of its neighbors is removed from the display.

In general, students of apparent motion have paid little attention to the dimming of the first stimulus, as well as to other suppression effects of motion that will be discussed later. Several writers have mentioned movement in their discussions of metacontrast suppression (Fehrer \& Raab, 1962; Kolers \& Rosner, 1960; Mayzner, Tresselt, \& Cohen, 1966; Toch, 1956; Werner, 1935), but the idea that the two phenomena may follow the same rules is recent (Fehrer \& Smith, 1962; Fehrer, 1965, 1966; Pollack, 1966).

The hypothesis of the present study was that 
metacontrast suppression represents an anomalous type of apparent motion, at least when it occurs between targets that are similar in energy and figural characteristics (Fehrer \& Smith, 1962; Kolers, 1962). The perceptual system is unable to resolve the simultaneous motions of a single object in two directions, and suppression results. In the threesquare display, a single object is set into apparent motion in two directions at once; in the disk-ring sequence, a stimulus is presented which would cause the original disk to grow in size even as it disappears. The metacontrast display provides cues to "impossible motion," much in the way that the well known drawings of Penrose and Penrose (1958) provide cues for impossible three-dimensional figures.

If metacontrast is impossible motion, it follows that the quality of metacontrast and of apparent motion should depend on the same variables. Presumably, suppression is maximal when the opposing tendencies to motion are strongest. In order to test this hypothesis, the dependence of apparent motion and of metacontrast on the temporal parameters of stimulation was studied.

In most studies of apparent motion, the durations of exposure of the first and the second stimuli are equal. The fourth law of Korte (1915) states that as the duration of exposure (D) is increased, the interval between the end of the first stimulus and the beginning of the second (ISI) must be decreased to obtain optimal motion. Subsequent studies have confirmed Korte's fourth law (Kolers, 1964; Neuhaus, 1930; Sgro, 1963), though the results of these studies differ in many particulars.

Pilot observations of both motion and metacontrast in our laboratory suggested that the complementarity between D and ISI is very nearly perfect: $D+I S I=$ Constant, for the perception of any degree of apparent motion. The sum of $D$ and ISI defines the stimulus-onset asynchrony (SOA) between the two exposures.

Previous studies of Korte's fourth law reported systematic deviations from a strict onset-onset law, but they did not agree on the direction of the discrepancy. For example, the optimal SOA for motion is a monotonically increasing function of $D$ in the data of Kolers (1964), and varies complexly with $D$ in the data of Neuhaus (1930). However, these and other parametric studies of apparent motion and metacontrast are difficult to interpret because the experimental set of the subject is rarely specified in sufficient detail. Apparent motion and metacontrast are labile phenomena, which depend critically on the observer's criterion. Some investigators (Kolers, 1962; Neuhaus, 1930) have responded to the criterion problem by using highly experienced and knowledgeable observers. This procedure may improve reliabllity, but it suffers from a crippling defect: The instructional set which an experienced observer finally adopts is unique and idiosyncratic, and cannot be reproduced at will in another laboratory. Consequently, discrepancies among different sets of results cannot be resolved.

In the present study, naive subjects served as observers, and an attempt was made to establish their set by the instructions, which are reproduced in full below.

\section{Subjects}

\section{METHOD}

Three Harvard and two Radcliffe undergraduates served for two 1 -h sessions on consecutive days. The first session was devoted to metacontrast, the second to apparent motion.

\section{Apparafus and Stimuli}

The $S$ was comfortably seated, with the back of his head supported at a distance of $130 \mathrm{~cm}$ from a Fairchild slave scope on which the stimuli appeared. The stimuli were three illuminated outline squares, $14 \mathrm{~mm}$ large, subtending 37 minutes of visual arc at the viewing distance. The distance between neighboring sides of the central and flanking squares was $7 \mathrm{~mm}$. A fixation cross was presented $7 \mathrm{~mm}$ above the middle of the central square. The $S$ initiated the display sequence by pressing a key. The fixation cross appeared, and was followed after 800 msec by the middle square, then by either the two flanking squares in the case of metacontrast, or the square on the right in the case of motion. The fixation cross remained in view until the sequence was completed.

The Fairchild scope was slaved to a DEC Type 340 scope, which was in turn controlled by a PDP-4 computer. Approximately $750 \mu \mathrm{sec}$ were required for a single complete cycle, during which every point of the display was illuminated once. The durations and intervals could be controlled to the nearest msec. The persistence of illumination on the Fairchild scope is negligible. The luminance of the display at an indefinite duration of exposure was approximately $1 \mathrm{~mL}$.

\section{Procedure}

The following instructions were read to the $S$; the metacontrast instructions were given on the first day and the motion instructions (in parentheses) on the second day:

"Our experiment today is concerned with an effect in perception which is called metacontrast (apparent motion). I shall be showing you three (two) squares on this scope, first one in the middle, then two others flanking it (then another beside it). Metacontrast (apparent motion) is sometimes obtained under these conditions.

"Perfect metacontrast is the case when you see only the two flanking squares and the middle 
square is not seen at all. Partial metacontrast is when the middle square is seen, but it is dim, faint, or incomplete.

("Perfect apparent motion is the case when you see only one square which moves smoothly from one position to the other, without changing in brightness along the way. Partial motion is the case when the starting and arrival positions can be seen as two squares, but there is motion between them).

"Your task is to rate each presentation according to how well what you see corresponds to this description of metacontrast (apparent motion). Use numbers for your ratings, as follows: The number 5 indicates that this was perfect metacontrast (apparent motion). The number 3 indicates that metacontrast (apparent motion) is only partial, but still quite marked. The number 0 indicates that what you see bears no resemblance at all to metacontrast (apparent motion). Use the other numbers to indicate various degrees of correspondence between the description and what you see."

Five exposure durations were studied: $25,50,75$, 100 , and $125 \mathrm{msec}$. The duration of exposure was the same for the first and for the second stimulus in the sequence. In a series of consecutive trials, devoted to a particular duration, the $S$ rated metacontrast or apparent motion at 11 values of stimulusonset asynchrony (SOA): $2,25,50 \ldots, 250 \mathrm{msec}$. The interval between successive trials was approximately 5 sec. The sequence of SOAs during a series was random. Five series of trials, one for each exposure duration, constituted a block. During the experimental session, four blocks were run, with a different random order of durations within each block. Altogether, there were 55 different conditions of exposure, and the $\mathrm{S}$ rated each condition four times.

Unknown to $S$, the first series of trials, conducted at a durection of $50 \mathrm{msec}$, was considered practice. Altogether, $S$ was dark adapted for at least $10 \mathrm{~min}$ before data collection began. $S$ communicated his ratings by intercom. E did not speak during the session except to announce short breaks between blocks and to answer direct questions, which were rare. All questions were answered by repeating relevant parts of the instructions.

After the termination of the main part of the second session, the instructions for ratings of motion were repeated, and three series of ratings were obtained with an exposure duration of $800 \mathrm{msec}$ and ISIs ranging between -100 and $+200 \mathrm{msec}$ (SOAs of $700 \mathrm{msec}$ to $900 \mathrm{msec}$ ).

\section{RESULTS}

Figure 1 presents average ratings of the quality of metacontrast and apparent motion as a function of SOA, for five values of $\mathrm{D}$. The curves in each graph would diverge if either the duration (D) or the interstimulus interval (ISI) separately determined the perceptual effect. However, the curves overlap almost perfectly, with the exception of the function for $\mathrm{D}=125 \mathrm{msec}$ in metacontrast. This curve is lowest in average level for four of the five Ss, and next to lowest for the remaining $S(p<.01)$. In accord with the major hypothesis of this study, results for motion and metacontrast are essentially identical. The only discrepancy was observed at SOA $=25 \mathrm{msec}$ where, for three Ss, ratings of motion were consistently higher than ratings of metacontrast. In both metacontrast and apparent motion, an onset-onset law fits the data very well. Good metacontrast and apparent motion are obtained even at negative values of ISI, when the second stimulus is shown before the first is removed. Both conclusions are confirmed within the separate data of each $\mathrm{S}$.

When the temporal overlap (negative ISI) of the two stimuli exceeds a critical value, motion is not seen. S sees a single square, then two squares, and finally the second square alone, in accord with the physical sequence of stimulation. Consequently, the onset-onset law breaks down at high values of $D$,

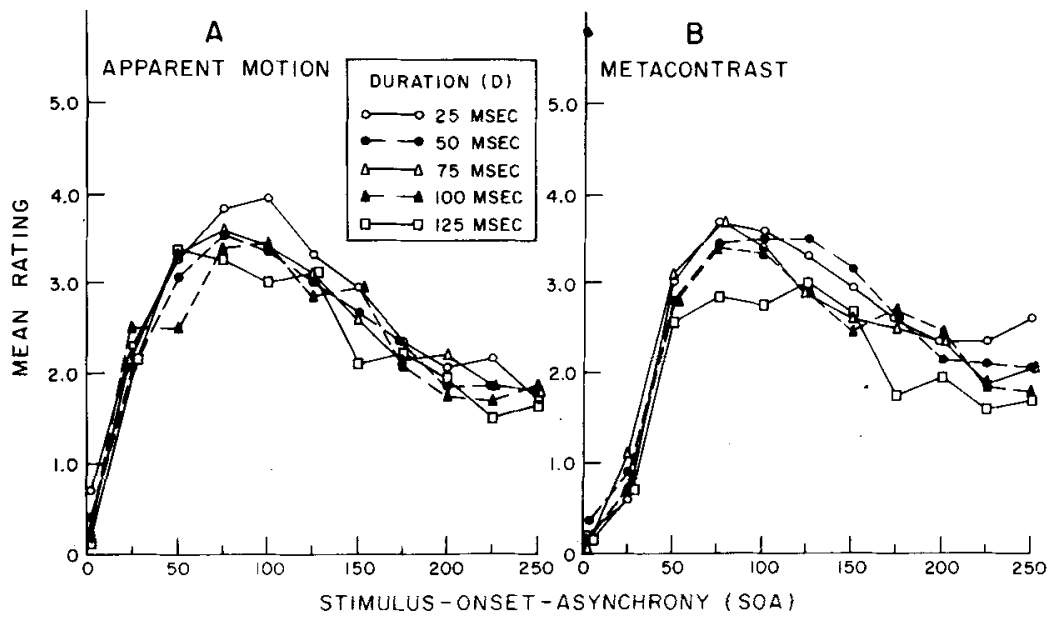

Fig. 1. Mean ratings of displays of two squares (A) for apparent motion and three squares (B) for metacontrast, as a function of stimulus-ónset asynchrony. Exposure duration is the parameter. Five observers rated each display four times. 


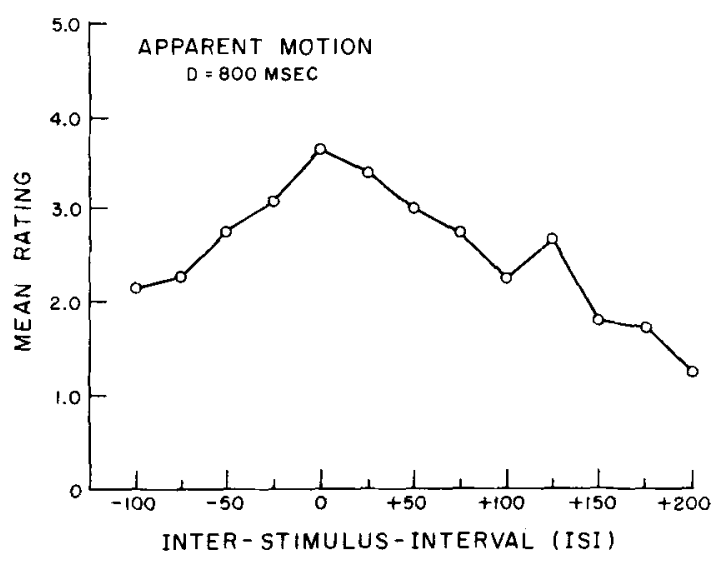

Fig. 2. Mean ratings of apparent motion as a function of interstimulus interval at an exposure duration of $800 \mathrm{msec}$. Five observers rated each display three times.

when the duration of overlap becomes too long. Optimal motion can be obtained when $D$ is long, but only if the second stimulus is presented near the time at which the first is removed. The $S$ sees a square, which is stationary for a while, then moves to another location. Figure 2 shows the dependence of the quality of apparent motion on ISI, for $D=800$ msec. Adequate apparent motion is obtained over a large range of ISIs, including negative values for which the onset of the second stimulus precedes the physical disappearance of the first. The peak of the function is at or near ISI $=0$, where the two events are simultaneous.

\section{Metacontrast}

\section{Discussion}

An interpretation of metacontrast has been advanced, in which suppression in the three-square display is the counterpart of optimal motion in the two square display. The hypothesis is supported by the similarity between the functions that relate the two effects to temporal parameters of stimulation. The present view of metacontrast is most similar to that of Fehrer, who has stressed the similarities between metacontrast suppression and apparent motion (Fehrer, 1965, 1966; Fehrer \& Raab, 1962; Fehrer \& Smith, 1962).

Mayzner and his colleagues (Mayzner et al, 1966, 1967) have reported observations which directly implicate motion in metacontrast suppression. They successively present at rapid rates the various letters of a word (e.g., SOMERSAULT), recycling the exposure repeatedly. At very fast rates of succession, the whole word is seen; at slower rates, the outcome depends on the sequencing of letters within the word. If the sequence permits a coherent organization of motion (leftward, rightward, inflowing or outflowing), that motion is perceived and the whole word is seen. When the letters are presented in an incoherent order, the letters that are pre- sented first in the sequence disappear, and are not seen even over many cycles of presentation. Thus, the word CHAIR may be seen as CAR. These data provide the most direct support for the interpretation of metacontrast suppression as a case of impossible motion.

Apparent motion is always a U-shaped function of SOA. Consequently, a theory which views metacontrast as a motion effect cannot explain those cases where suppression is maximal at SOA $=0$ and decreases monotonically with SOA (Eriksen \& Collins, 1964, 1965; Schiller, 1965; Schiller \& Smith, 1966). Other mechanisms must be invoked to account for these monotone functions (Fehrer \& Smith, 1962). Kolers (1962) concluded from a series of experiments with disks and rings that monotone functions are obtained when a large difference of duration, intensity, or contrast favors the masking ring over the target disk. U-shaped functions are obtained when the target and the mask are more similar. Fehrer and Smith (1962) obtained comparable results in a three-square display, by varying the ratio of Iuminances of the target and masking squares. $U$-shaped functions were obtained when the ratio was near unity, and monotone functions when the ratio was low. Fehrer and Smith (1962) pointed out that the low ratios are favorable to the occurrence of simultaneous contrast.

Simultaneous contrast is a special case of lateral interaction between neighboring visual stimuli. The outcome of these interactions is a reduction of the brightness or contrast of the weaker stimulus (Heinemann, 1955), an elevation of difference thresholds in the vicinity of contours (Fry \& Bartley, 1935), and a reduction of acuity (Flom, Weymouth, \& Kahneman, 1963). Lateral inhibition disproportionately affects the weaker of two interacting stimuli (Hartline \& Ratliff, 1957), and its effects increase with increasing imbalance between them. When a strong and a weak stimulus are presented at about the same time, the response to the weaker stimulus may be completely suppressed (Ratliff, Hartline, \& Miller, 1963). On the other hand, suppression is primarily a motion effect when stimulus energies are more nearly equal. U-shaped functions are then obtained, and the extent of masking depends on the figural relations between the figures (Fehrer, 1965, 1966).

Since apparent motion can be obtained dichoptically (Smith, 1948), it must be determined fairly late in the sequence of visual processing. A theory which explains metacontrast in terms of motion is therefore consistent with the finding that a stimulus which is perceptually suppressed by metacontrast may nonetheless elicit a behavioral response (Fehrer \& Raab, 1962; Fehrer \& Blederman, 1962; Harrison \& Fox, 1966; Schiller \& Smith, 1966) and an essentially intact cortical evoked response (Schlller \& 
Chorover, 1966). The occurrence of metacontrast suppression in dichoptic presentations was amply demonstrated by Kolers and Rosner (1960), and has been confirmed in another display by Mayzner et al (1967). There is no justification for the assumption that metacontrast suppression is a retinal effect (Alpern, 1965; Alpern \& Rushton, 1965).

\section{Apparent Motion}

Our discussion of suppression in metacontrast has related that effect to the phenomenon of apparent motion. It is of some theoretical importance that this relation is mutual. Suppression effects are intimately involved in the perception of apparent motion. The following observations support that statement:

(1) The reduction in brightness and contrast of the first object in a motion display was mentioned earlier. This reduction is obtained at values of SOA which are too short for optimal motion. The effect is included in Wertheimer's description of partial motion (Wertheimer, 1912). When the objects are dark on a lighter background, the contrast of the first object is markedly reduced.

(2) With brief exposure durations (up to 100-150 msec in many conditions) the experience is not of a stationary object that moves to a new location. but of a moving object. Of course, the first object would be perceived as stationary if presented alone, but that percept is entirely suppressed when motion is seen.

(3) Excellent apparent motion is obtained even for negative values of ISI, when the two objects are in fact present side by side for as long as 50-75 msec. The percept that would correspond to the simultaneous presence of two objects in the field is suppressed.

(4) The following demonstration is easily arranged: Two squares are presented together for $800 \mathrm{msec}$. After an SOA of $750 \mathrm{msec}$, a third square is presented near one of the original squares, which is then seen in motion. When observers are required to judge which of the two initial squares was the first to disappear, they consistently select the one that was set into motion. Thus, motion curtails the normal persistence of the percelved stationary square.

(5) Suppression is directly observable when a homogeneously illuminated rectangle is shown twice in rapid succession with a slight lateral shift in position between the first and second exposures. The central area where the two exposures overlap should appear brighter than the two lateral areas which are illuminated only once, by temporal summation of brightness. This is indeed observed at very short SOAs, At slightly longer SOAs, which are still too brief for optimal motion, the forward edge of the "moving" rectangle is seen as markedly brighter than both the area of overlap and the trail- ing edge. 2 This distribution of apparent brightness does not correspond to the distribution of stimulating energy, and obviously involves considerable suppression.

In these examples, the perception of motion is not merely a filler for the "dead time" between two successive percepts (Koffka, 1935). A radical alteration of the perception of the first object is caused by the presentation of the second. The percept which the first object would normally elicit is suppressed and replaced by another. Thus, apparent motion probably represents the most common type of retroactive interaction in visual perception.

How are such retroactive effects to be explained? The main theories which have been advanced to account for metacontrast and backward masking cannot be applied to motion.

Metacontrast suppression has sometimes been explained (Kolers, 1962; Werner, 1935) on the assumption that contour formation takes time; the contour that is shared by target disk and masking ring is appropriated by the ring before the disk is formed. This interpretation is inapplicable to the suppression effects which accompany beta motion between two squares that do not share a contour.

Another common interpretation of backward masking and metacontrast suppression attributes these effects to overtake (e.g., Crawford, 1947; Donchin, 1967). It is said that the response to the second stimulus overtakes the response to the first stimulus and interferes with it. However, the idea of different latencies is not applicable when the stimuli are equal in luminance, as they are in most studies of motion. In addition, it is easy to produce cascading of apparent motion with a series of stimuli, and the notion that the latencies of successive responses are progressively shorter is clearly untenable.

Although complete overtake of the first response by the second is very doubtful as an explanation of motion, there is certainly much overlap between the perceptual responses to the two stimuli. The response which a brief visual stimulus elicits lasts much longer than does the stimulus. This conclusion has been confirmed for the ERG (e.g., Johnson,

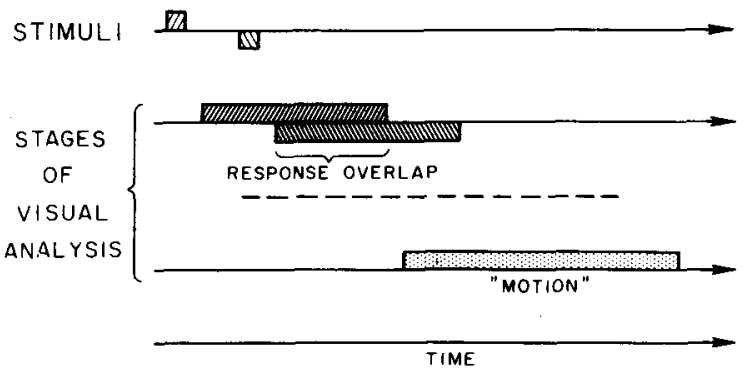

Fig. 3. Responses to brief stimuli at two stages of visual analysis. Possible intermediate stages are not indicated. 


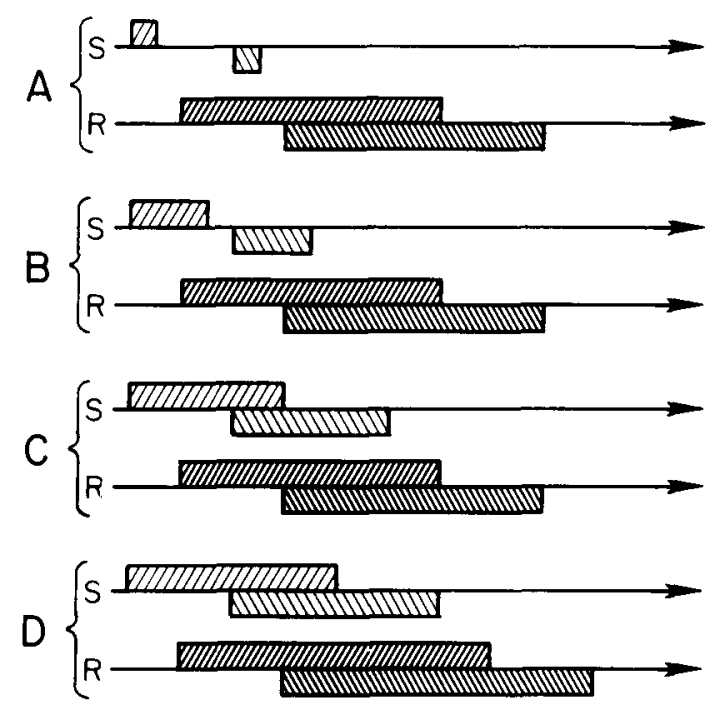

Fig. 4. Derivation of the onset-onset law for brief stimuli. In $A, B$ and $C$, the responses $(R)$ to brief stimuli ( $S$ ) are identical in duration and overlap to the same extent. The response is longer in $D$, and overlap is correspondingly prolonged.

1958), the evoked potential (e.g., Wicke, Donchin, \& Lindsley, 1963), and conscious visual experience (e.g., Mackworth, 1963; Sperling, 1960). At these various levels of visual response, the duration of the response appears to be approximately the same for brief stimuli (less than 100-150 $\mathrm{msec}$ ), regardless of their duration.

If the response to a brief stimulus lasts longer than the stimulus, the responses to two stimuli which follow one another in quick succession must overlap in time, unless one makes the doubtful assumption that the first response is sharply interrupted as soon as the second begins. The apparently retroactive effects of suppression and motion are not retroactive at all, if the responses to successive stimuli occur side by side at some level of analysis, though one of them may have started earlier and the other is the last to cease. In order to account for the effects of temporal parameters on perceived motion, the further assumption is required that the amount of temporal overlap between successive responses at one level of analysis is itself the effective stimulus for the response of a subsequent level. In these terms, motion is seen when a period of response to the first stimulus alone is followed by a period of overlap-provided that the overlap is of intermediate duration-and the overlap is itself followed by a period of response to the second stimulus alone. Figure 3 is a schematic illustration of such a model. The levels at which the responses are parallel and the level at which they interact are not specified, and the relative values of response latency and response persistence are arbitrary. In spite of these limitations, Fig. 3 illustrates that
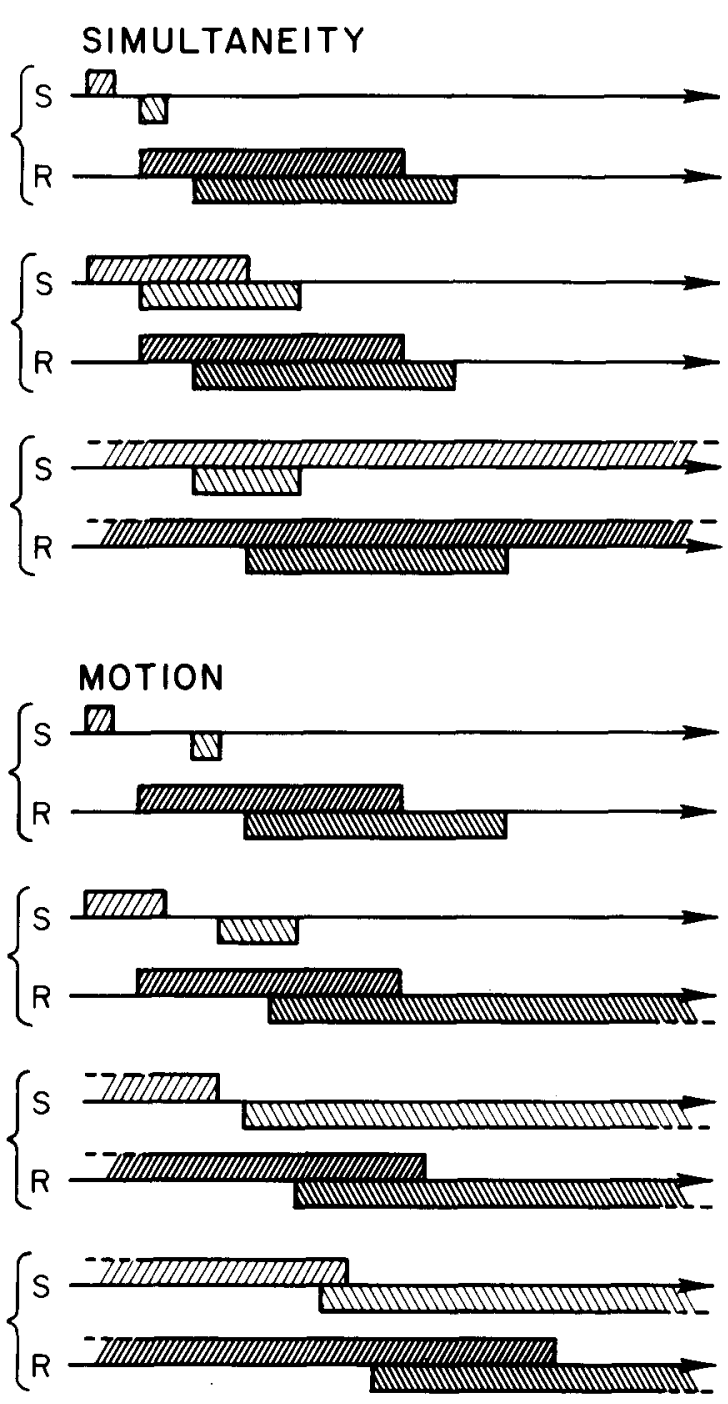

\section{SUCCESSIVENESS}
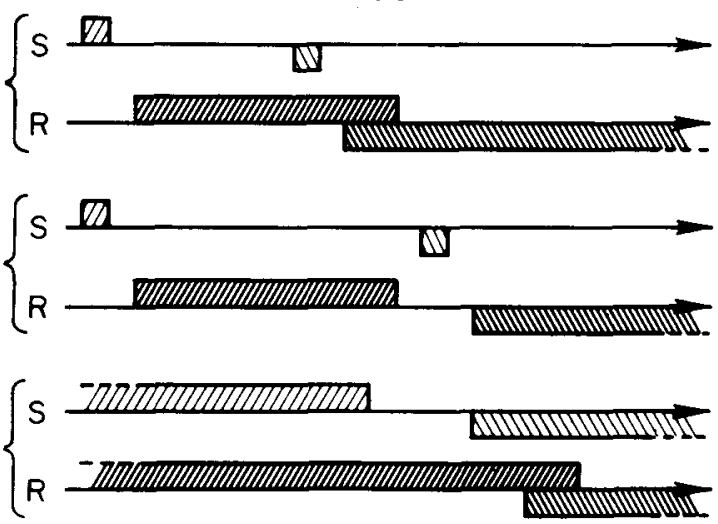

Fig. 5. Schematic summary of conditions for apparent simultaneity (long response overlap), motion, and successiveness (overlap brief or absent) for both brief and more prolonged stimuli. 
the response of "motion" cannot ke initiated until information is received that the first stimulus has been removed while the second is still present. The model is consistent with the well known fact that the duration of the second stimulus is essentially irrelevant to the perception of motion, unless that duration is very brief. As was mentioned earlier, the responses to brief stimuli are relatively prolonged, and the duration of response overlap therefore depends mainly on SOA and on the duration of the first stimulus.

The suggestion that the duration of response to brief stimuli is largely independent of the duration of exposure entails a similar independence for response overlap. Overlap depends only on SOA, as Fig. 4 illustrates. This is the onset-onset law which the present study confirmed for both motion and metacontrast. There is evidence (Donchin, 1967) that SOA is also a most important variable in backward masking by a flash of light over the area of the target, and a similar model could be invoked to account for that result. SOA is the same for all conditions of Fig. 4. In (a), (b), and (c), the stimuli are brief and the responses to them are assumed to be equal in duration. Response overlap is also constant, and any consequences of overlap, such as motion or suppression, would be equally evident in the three cases. In (d), stimulus duration is longer in the range where duration of the response increases with that of the stimulus. Consequently, response overlap is greater in (d) than in the other cases, perhaps long enough for an observer to report that the two objects were present together in his field of view.

Figure 5 summarizes in terms of response overlap the conditions for the occurrence of simultanelty, motion, and successiveness, with stimuli of different durations. An arbitrary value was assumed for the persistence of long stimuli. The figure makes it clear that response overlap aepends on SOA for brief stimuli and on ISI for longer ones. As a heuristic model, Fig. 5 adequately summarizes the stimulus conditions under which motion is seen. The model also incorporates a plausible solution to the vexing question of retroactive effects in perception. However, a profound gap still separates such a descriptive model from an adequate theory of apparent motion.

\section{References}

Alpem, M. Metacontrast: historical introduction. Amer. J. Optom., $1952,29,631-646$.

Alpem, M. Metacontrast. J. Opt. Soc. Amer., 1953, 43, 648-657. Alpem, M. Rod-cone independence in the after-flash effect. $J$. Physiol., 1965, 176, 462-472.

Alpem, M., \& Rushton, W. A. H. The specificity of the cone interaction in the after-flash effect. $J$. Phy siol., 1965, 176, 473-482.

Crawford, B. H. Visual adaptation in relation to brief conditioning stimuli. Proc. Roy. Soc. Lond., 1947, 134B, 283-302.

Donchin, E. Retroactive visual masking: effects of test flash duration on masking interval. Vision Res., 1967, 7, 79-89.
Eriksen, C. W., \& Collins, J. F. Backward masking in vision. Psychon. Sci., 1964, 1, 101-102.

Eriksen, C. W., \& Collins, J. F. A reinterpretation of one form of backward and forward masking in visual perception. J. exp. Psychol., 1965, 70, 343-351.

Fehrer, E. Contribution of perceptual segregation to the relationship between stimulus similarity and backward masking. Percept. mot. skills, 1965, 21, 27-33.

Fehrer, E. Effect of stimulus similarity on retroactive masking. J. exp. Psychol., 1966, 71, 612-615

Fehrer, E., \& Biederman, I. A comparison of reaction and verbal report in the detection of masked stimuli. J, exp. Psychol., $1962,64,126-130$.

Fehrer, E., \& Raab, D. Reaction time to stimuli masked by metacontrast. J. exp. Psychol, 1962, 63, 143-147.

Fehrer, E., S Smith. E. Effect of luminance ratio on masking. Percept. mot. Skills, 1962, 14, 243-253.

Flom, M. C., Weymouth, F. W., \& Kahneman, D. Visual resolution and contour interaction. J. Opt. Soc. Amer., 1963, 53, 1026-1032.

Fry, G. A., \& Bartley, S. H. The effect of one border in the visual field upon the threshold of another. Amer. J. Physiol., 1935, $112,414-421$.

Harrison, K., \& Fox, R. Replication of reaction time to stimuli marked by metacontrast. J. exp. Psychol., 1966, 71, 162-163.

Hartline, H. K., \& Ratliff, F. Inhibitory interaction of receptor units in the eye of Limulus. J. gen. Physiol., 1957, 40, 357-376.

Heinemann, E. G. Simultaneous brightness induction as a function of inducing and test-field luminances. J. exp. Psychol., 1955, $50,89-96$.

Johnson, E. P. The character of the B-wave in the human ERG. A.M.A. Arch. Ophthal., 1958, 60, 565-591.

Kahneman, D. Method, findings and theory in studies of visual masking. (Submitted for publication, 1967).

Koffka, K. Principles of gestalt psychology. New York: Harcourt, Brace, 1935.

Kolers, P. A. Intensity and contour effects in visual masking. Vision Res., 1962, 2, 277-294.

Kolers, P. A. The illusion of movement. Scient. American, 1964, 211, 98-106.

Kolers, P. A., \& Rosner, B. S. On visual masking (metacontrast): dichoptic observation. Amer. J. Psychol., 1960, 73, 2-21.

Korte, A. Kinematoskopische Untersuchungen. Z. Psychol., 1915, $72,193-296$.

Mackworth, J. E. The duration of the visual image. Canad. $J$. Psychol., 1963, 17, 62-81.

Maymer, M. S., Tresselt, M. E., \& Cohen, A. Preliminary findings on some effects of very fast sequential input rates on perception. Psychon. Sci., 1966, 6, 513-514.

Mayzer, M. S., Tresselt, M. E., Adrignolo, A. J., \& Cohen, A. Further preliminary findings on some effects of very fast sequential input rates on perception. Psychon. Sci., 1967, 7, 281-282

Neuhaus, V. Experimentelle Untersuchung der Scheinbewegung. Arch. f.d. ges. Psychol., 1930, 75, 315-458.

Penrose, L. A., \& Penrose, R. Impossible objects: a special type of visual illusion. Brit. J. Psychol., 1958, 49, 31-33.

Pollack, R. H. Initial stimulus duration and the temporal range of apparent movement. Psychon. Sci., 1966, 5, 165-166.

Raab, D. H. Backward masking. Psychol. Bull., 1963, 60, 118-129.

Ratliff, F., Hartline, H. K., \& Miller, W. H. Spatial and temporal aspects of retinal interactions. J. Opt. Soc. Amer., 1963, 53, $110-120$.

Schiller, P.H. Detection in metacontrast as determined by a method of comparisons. Percept. mot. Skills, 1965, 20, 47-50.

Schiller, P. H., \& Chorover, S. L. Metacontrast: its relation to evoked potentials. Science, 1966, 153, 1398-1401.

Schiller, P. H., \& Smith, M. Detection in metacontrast. J. exp. Psychol., 1966, 71, 32-39.

Sgro, F. J. Beta motion thresholds. J. exp. Psychol., 1963, 66, 281-285.

Smith, K. R. Visual apparent movement in the absence of neural interaction. Amer. J. Psychol., 1948, 61, 73-78.

Sperling, G. The information available in brief visual presentations, Psychol. Monogr., 1960, 74, 1-29. 
Spigel, J. M. (Ed.) Readings in the study of visually perceived movement. New York: Harper and Row, 1965.

Toch, H. H. The perceptual elaboration of stroboscopic presentations. Amer. J. Psychol., 1956, 69, 345-358.

Werner, H. Studies on contour: I. Qualitative analyses. Amer. J. Psychol., 1935, 47, 40-64.

Werner, H. Studies on contour: Strobostereoscopic phenomena Amer. J. Psychol., 1940, 53, 418-422.

Wertheimer, M. Experimentelle Studien über das Sehen von Bewegung. Z. Psychol., 1912, 61, 161-265.

Wicke, J. D., Donchin, E., \& Lindsley, D. B. Visual evoked potentials as a function of flash luminance and duration. Science, $1964,146,83-85$.

\section{Notes}

1. Now at Hebrew University, Jerusalem, Israel. This study is an outgrowth of an extensive series of pilot observations carried out in collaboration with Dr. J. S. Bruner. Kenneth Ledeen did the programming work, and the assistance of Ruth Wolman and Linda Onuska was most valuable. The study was supported in part by grant No. $\mathrm{P}$ 01-MH-12623 from the National Institute of Mental Health and in part by grant No. GS 1153 from the National Science Foundation to Harvard University, Center for Cognitive Studies. 2. I thank Dr. David N. Lee for this demonstration.

(Accepted for publication August 15, 1967.) 